\title{
Las salvaguardas arancelarias en tiempo de crisis*
}

\section{Tariff Safeguards in Time of Crisis}

\section{Óscar Cruz Barney**}

SUMARIO: I. Introducción: Crisis y comercio internacional. II. Las medidas de salvaguarda, el artículo XIX del GATT y el Acuerdo sobre Salvaguardas de 1994. III. Crisis económica y salvaguardas. IV. Crisis económica y medidas antidumping. V. Las medidas de salvaguarda en los mecanismos de integración regional iberoamericano: Mercosur y ALADI. VI. Conclusión.

VII. Bibliografía, hemerografía y fuentes.

* Artículo recibido el 12 de agosto de 2011 y aprobado para publicación el 28 de septiembre de 2011.

** Académico de Número de la Academia Internacional de Derecho Aduanero. Investigador en el Instituto de Investigaciones Jurídicas de la UNAM, SNI III. Cruz Distinguida de Primera Clase de la Orden de San Raimundo de Peñafort.

D. R. (C) 2012. Universidad Nacional Autónoma de México-Instituto de Investigaciones Jurídicas. Anuario Mexicano de Derecho Internacional, vol. XII, 2012, pp. 859-898, 
RESUMEN: La crisis económica mundial ha tenido como consecuencia la contracción de los mercados externos en la demanda de los productos fabricados localmente, ocasionando excedentes en la producción nacional derivada de la caída en la demanda tanto nacional como internacional y la cancelación de operaciones previamente pactadas.

Dichos excedentes de producción se verán reducidos mediante la disminución en los niveles de producción, las posibles ventas internas y la colocación de los mismos en los mercados internacionales que se mantengan abiertos ante y pese a la crisis.

Frente a esta posibilidad las salvaguardas comerciales se consideran adecuadas para proteger a los productores nacionales en contra de dificultades económicas no previstas resultantes o no de la liberalización comercial. La idea es que los países afectados estén en una mejor disposición para reducir sus barreras al comercio y que la flexibilidad dada por las salvaguardas incremente en el largo plazo la estabilidad del sistema del comercio mundial.

Palabras clave: salvaguardas, crisis económica, comercio, GATT, integración económica.

ABSTRACT: The global economic crisis has resulted in the contraction of the external market demand for products manufactured locally, causing domestic production surpluses resulting from the fall in domestic and international demand operations and cancellation of previously agreed operations.

These production surpluses will be reduced by dropping the levels of production, domestic sales and the possible placement of them in international markets which remain open despite the crisis.

Faced with this possibility the commercial safeguards are considered adequate to protect domestic producers against unanticipated economic difficulties resulting or not from trade liberalization. The idea is that the affected countries will be in a better position to reduce their barriers to trade and that the flexibility provided by the safeguards in the longer term increases the stability of the global trading system. Keywords: safeguards, economic crisis, trade, GATT, economic integration.

RÉSUMÉ: La crise économique mondiale a eu par conséquence la contraction des marchés extérieurs dans la demande des produits fabriqués localement, entraînant des excédents de production nationale qui résulterait de la chute de la demande en tant que national comme internationales et l'annulation des convenues antérieurement.

Ces excédents de production seront réduits par moyen de la diminution dans les niveaux de production, les possibles ventes nationales et la mise en place éventuelle d'entre eux sur les marchés internationaux de rester ouvert malgré la crise.

Face à cette possibilité les sauvegardes commerciales sont considérées comme adéquates pour protéger aux producteurs nationaux contre les difficultés économiques imprévues résultants ou non de la libéralisation des échanges. L'idée est que les pays touchés soient dans une meilleure position pour réduire les obstacles au commerce et que la flexibilité offerte par les sauvegardes, pour augmenter à long terme la stabilité du système commercial mondial.

Mots-clés: sauvegardes, la crise économique, commerce, GATT, l'intégration économique. 


\section{INTRODUCCIÓN: CRISIS Y COMERCIO INTERNACIONAL.}

La creación de un espacio único de circulación de bienes y servicios, así como de capitales es uno de los objetivos del fenómeno de la globalización o mundialización, en el que la convergencia implícita o bien programada de los intereses de las empresas transnacionales es necesaria para lograr las metas planteadas. ${ }^{1}$

Los postulados de la doctrina del libre comercio sostienen que para lograr las metas planteadas en la Carta de La Habana y particularmente en el GATT, suponen que el comercio mundial se incrementará a través del intercambio de mercancías basado en la tesis de la "ventaja comparativa" en donde los mercados se autorregularán libre y automáticamente. Si bien, se supone que en el largo plazo, los productores se transformarán y serán más eficientes o bien destinarán sus recursos a otras actividades más competitivas.

Empero, la realidad imperante muestra que la pretendida aplicación simplista de estos postulados puede producir daño y dislocación del mercado a los productores nacionales, especialmente a los menos eficientes.

Sobre todo si consideramos que las afectaciones a las economías nacionales producen efectos a nivel global. Viceversa, la repercusión de las crisis económicas internacionales en las empresas locales. Asimismo, la globalización financiera que beneficia a los países mediante una mejor distribución de los recursos, también tiene como consecuencia que los problemas en un mercado determinado se desplacen a otros mercados con gran rapidez. Pensemos en la "crisis del petróleo" de 1974-1975 (una crisis ocasionada por una sobreproducción de bienes industriales) originada en los Estados Unidos y Europa con severas consecuencias en las economías latinoamericanas y en una caída del comercio mundial.

La crisis de 1994-1995 originada en México, denominados sus efectos como "efecto tequila" que resultó en afectaciones a las economías de la región y de los Estados Unidos. A esta crisis se le caracteriza por la doctrina como la primera crisis en la actual etapa de globalización de

1 Fernández Rozas, José Carlos, Sistema del comercio internacional, Madrid, Civitas, 2001, p. 64. 
la economía mundial que pudo haberse transformado en crisis del sistema en su conjunto de no haberse llevado a cabo las operaciones de rescate financiero. ${ }^{2}$

Otros escenarios de crisis se plantearon en 1997 y 1998 en el sudeste asiático y Rusia. Asimismo, la crisis iniciada en Argentina en 2000 por la pérdida de peso de su sector industrial y por la devaluación del real brasileño en enero de 1999.

La crisis económica iniciada en 2008 se enmarca en los periodos en que suelen moverse los mercados financieros: euforia y pánico, estando nuevamente en un periodo de creciente alarma. Entre los elementos de la crisis se encuentra el hecho de que los mercados financieros de derivados son de gran tamaño con operaciones cada vez más complejas y niveles de apalancamiento cada vez mayores. Por su parte, el mercado interbancario jugó un papel fundamental al ser fuente de liquidez y transmisor de las perturbaciones económicas. ${ }^{3}$

Se considera que la crisis de 2008 se ha producido como consecuencia de una política monetaria excesivamente expansiva que dio lugar a una burbuja inmobiliaria y a un exceso de crédito. La utilización de productos financieros excesivamente complejos a fin de conseguir mayores rentas llevó a una erosión del sentido del riesgo. ${ }^{4}$

Queda de manifiesto cómo la actividad económica se desarrolla conforme a dos elementos fundamentales que son la mundialización y la repercusión del sector financiero sobre el mundial.

\section{LAS MEDIDAS DE SALVAGUARDA, EL ARTÍCULO XIX DEL GATT Y EL ACUERDo SOBRE SALVAGUARDAS DE 1994}

En los hechos y más en un escenario de crisis, los pretendidos cambios en la eficiencia de los productores no se dan, o bien, en el mejor de los

Ibidem, p. 68.

3 XIV Observatorio Económico FAES, Madrid, 15 de octubre de 2008. Consultable en http: / / www.fundacionfaes.org/record_file/filename/2231/14_OBSERVATORIO_OK_FINALO3. pdf. Consultado el 5 de septiembre de 2011.

4 Ibidem, p. 8. 
casos, no se dan a la velocidad necesaria para evitar o paliar los efectos negativos; no hay en estas circunstancias ni la capacidad financiera para apoyarlos ni los recursos humanos suficientes que faciliten las transformaciones requeridas por la producción nacional.

Por ello la pertinencia de reconocer esta situación primeramente y luego de crear respuestas adecuadas para evitar los daños, fueron advertidos oportunamente por los creadores del GATT, pero al mismo tiempo, se ocuparon de que el acceso a tales remedios no fuese fácil sino sólo en casos que realmente se justificasen.

La lucha por alcanzar las metas del comercio libre continuaron presentes y en esta pugna de situaciones que son contradictorias entre sí, se elaboraron mecanismos para ordenar las importaciones correctas.

Los Estados Unidos promovieron dichos instrumentos ante la presión, por una parte, de sus productores que constantemente criticaban a su gobierno por ser tan "generoso" con los proveedores extranjeros abriéndoles de manera indiscriminada las puertas de su mercado, y por la otra, de sus industriales que pretendían acceder a los mercados mundiales con sus productos altamente competitivos, a cambio de abrir el propio.

De ahí nació la llamada originalmente escape clause, que más tarde se convertiría en la cláusula de salvaguarda ${ }^{5}$ y daría pie a toda una gama de fórmulas protectoras del producto doméstico, mediante las que se cubriera a los mismos de los efectos negativos de la apertura comercial.

En el foro de las negociaciones del Acuerdo General de Aranceles Aduaneros y Comercio y en el borrador de la Carta Constitutiva de la fallida Organización Internacional de Comercio ${ }^{6}$ se reflejó esta preocu-

5 Una salvaguarda se refiere a medidas temporales de protección de las industrias domésticas frente a incrementos en las importaciones que causen o amenacen causar un daño serio a dichas industrias. Véase Lee, Yong-Shik, "Critical issues in the Application of the WTO Rules on Safeguards. In the Light of the Recent Panel Reports and the Appellate Body Decisions", Journal of World Trade, Ginebra, Kluwer Law International, vol. 34, núm. 2, abril de 2000, p. 131. Véase para México, Cruz Miramontes, Rodolfo, "Aspectos generales del intercambio comercial internacional. Su regulación y efectos, en particular a las relaciones entre México y los Estados Unidos de Norteamérica”, en Barra Mexicana, Colegio de Abogados, La nueva Ley de Comercio Exterior, México, Porrúa, 1987. Asimismo Saldaña Pérez, Juan Manuel, Comercio Internacional, Porrúa, 2008.

6 Artículo 40. "Emergency Action on Imports of Particular Products", Text of Geneva Draft Charter for an International Trade Organization-International Conciliation, Nueva York, octubre de 1947. 
pación quedando a la postre sólo lo negociado en el GATT, presente en el artículo XIX. La pertinencia de contar con esta disposición era de gran interés para el gobierno norteamericano por lo que fue el patrocinador y promotor de la cláusula,${ }^{7}$ cuyo origen se remonta al Tratado de Comercio entre México y los Estados Unidos de América celebrado el 23 de diciembre de 1942 que entró en vigor en $1943,{ }^{8}$ en donde por vez primera se contempla una cláusula de escape de carácter general. ${ }^{9}$ En febrero de $1947^{10}$ se obligó al Poder Ejecutivo estadounidense a incluir en cualquier tratado comercial que celebrase, la cláusula señalada.

La razón para incluir una cláusula de esta naturaleza estribó en la necesidad de impulsar la liberalización comercial y fomentar la flexibilidad en los regímenes de comercio. Se afirma que precisamente el artículo XIX del GATT sostiene la idea de que las restricciones pactadas son consistentes con el propio GATT pese a las prohibiciones impuestas por el artículo XI. ${ }^{11}$

Las salvaguardas se consideraron necesarias para proteger a los productores nacionales en contra de dificultades económicas no previstas resultantes de la liberalización comercial. Se pensó que con la existencia de una excepción al cumplimiento de las obligaciones de liberalización comercial en circunstancias extremas, los países estarían en una mejor disposición para reducir sus barreras al comercio y que la flexibilidad dada por las salvaguardas incrementaría en el largo plazo la estabilidad del sistema del comercio mundial. ${ }^{12}$

Como resultado de la Ronda Uruguay del GATT se dio a la luz el Acuerdo sobre Salvaguardas (en lo sucesivo ASG), que se elaboró reco-

7 "The GATT escape clause, Art. XIX was a result of United States desires", Jackson, John, World Trade and the Law of GATT, USA, 1969, p. 553. Executive Branch GATT Studies Committee on finance United States Senate, March 1974, p. 123; Bahla, Raj y Kennedy Kevin, World Trade Law, USA, Lexis Law Publishing, 1998, p. 899.

8 Tratado de Comercio entre México y los Estados Unidos de América celebrado el 23 de diciembre de 1942.

9 Trebilcock, Michael J. y Howse, Robert, The regulation of international trade, Londres, Routledge, 1995, p. 163.

10 Exec. Order no. 9832,3 C.F.R. Secc. 624, 625 (II, 25 - 1947).

11 Jackson, John H., The jurisprudence of GATT \& theWTO, Cambridge, Cambridge University Press, 2000, p. 81.

12 Trebilcock, Michael J. y Robert Howse, op. cit., p. 163. 
nociendo la necesidad de aclarar y reforzar las disciplinas del GATT de 1994, y concretamente las de su artículo XIX, de restablecer el control multilateral sobre las salvaguardas y de suprimir las medidas que escapen a tal control.

Uno de los mayores logros del Acuerdo citado fue dejar de lado las denominadas "Grey Area Measures" o "medidas de la zona gris" como son las restricciones voluntarias a la exportación y los acuerdos de comercialización ordenada. Estos instrumentos comunes para la protección de las industrias domésticas en los años ochenta fueron considerados como distorsionantes del comercio por los negociadores de la Ronda Uruguay del GATT, por lo que decidieron prohibirlos en el artículo 11 del $\mathrm{ASG}^{13}$ que estableció en su inciso $b$ que ningún miembro trataría de adoptar, adoptaría ni mantendría limitaciones voluntarias de las exportaciones, acuerdos de comercialización ordenada u otras medidas similares respecto de las exportaciones o las importaciones. ${ }^{14}$

El artículo XIX del GATT ${ }^{15}$ reza así en la parte conducente:

Artículo XIX: Medidas de urgencia sobre la importación de productos determinados

1. a) Si, como consecuencia de la evolución imprevista de las circunstancias y por efecto de las obligaciones, incluidas las concesiones arancelarias, contraídas por una parte contratante en virtud del presente Acuerdo, las importaciones de un producto en el territorio de esta parte contratante han aumentado en tal cantidad y se realizan en condiciones tales que causan o amenazan causar un daño grave a los productores nacionales de productos similares o directamente competidores en ese territorio, dicha parte contratante podrá, en la medida y durante el tiempo que sean necesarios para prevenir o reparar ese daño, suspender total o parcialmente la obligación contraída con respecto a dicho producto o retirar o modificar la concesión.

13 Lee, Yong-Shik, “Critical issues...”, cit., p. 131.

${ }_{14}$ Si bien existe la preocupación de que el acuerdo entre Canadá y Estados Unidos en el caso de madera suave viole esta disposición. Véase Lee, Yong-Shik,"Revival of Grey-Area Measures? The US-Canada Softwood Lumber Agreement: Conflict with the WTO Agreement on Safeguards", Journal of World Trade, Ginebra, Kluwer Law International, vol. 36, núm. 1, febrero de 2002, pp. 159 y ss.

15 Jackson, John H., World Trade..., cit, pp. 554 y 555; id., The World Trading System, 2a. ed., Estados Unidos, MIT Press, 2002, pp. 179 y 180. 
b) Si una parte contratante ha otorgado una concesión relativa a una preferencia y el producto al cual se aplica es importado en un territorio de dicha parte contratante en las circunstancias enunciadas en el apartado a) de este párrafo, en forma tal que cause o amenace causar un daño grave a los productores de productos similares o directamente competidores, establecidos en el territorio de la parte contratante que se beneficie o se haya beneficiado de dicha preferencia, esta parte contratante podrá presentar una petición a la parte contratante importadora, la cual podrá suspender entonces total o parcialmente la obligación contraída o retirar o modificar la concesión relativa a dicho producto, en la medida y durante el tiempo que sean necesarios para prevenir o reparar ese daño.

2. Antes de que una parte contratante adopte medidas de conformidad con las disposiciones del párrafo 1 de este artículo, lo notificará por escrito a las PARTES CONTRATANTES con la mayor anticipación posible. Les facilitará además, así como a las partes contratantes que tengan un interés substancial como exportadoras del producto de que se trate, la oportunidad de examinar con ella las medidas que se proponga adoptar. Cuando se efectúe dicha notificación previa con respecto a una concesión relativa a una preferencia, se mencionará a la parte contratante que haya solicitado la adopción de dicha medida. En circunstancias críticas, en las que cualquier demora entrañaría un perjuicio difícilmente reparable, las medidas previstas en el párrafo 1 de este artículo podrán ser adoptadas provisionalmente sin consulta previa, a condición de que ésta se efectúe inmediatamente después de que se hayan adoptado las medidas citadas. ${ }^{16}$

Existe cierta controversia en el sentido de si las disposiciones del citado artículo XIX siguen siendo aplicables o no a partir de la entrada en vigor del Acuerdo sobre Salvaguardas. Este tema se planteó por vez primera en los casos Corea —Medida de salvaguarda definitiva impuesta a las importaciones de determinados productos lácteos ${ }^{17}$ y Argentina-Medidas de salvaguarda impuestas a las importaciones de calzado ${ }^{18}$ en los que las partes reclamadas consideraron que el único documento aplicable en la imposición de medidas de salvaguarda era el ASG, mientras que las

16 Con el propósito de analizar los puntos más relevantes de los párrafos anteriores, suspenderemos la transcripción textual del artículo, dejando para más adelante el resto del mismo constituido solamente por el párrafo 3.

17 WT/DS98/R, 21 de junio de 1999, Informe del Grupo Especial.

18 WT/DS121/R, 25 de junio de 1999, Informe del Grupo Especial. 
comunidades europeas señalaron que el artículo XIX y el ASG eran de aplicación acumulativa.

En el primero de los casos, el Grupo Especial consideró que los términos y las prescripciones del párrafo 1 del artículo XIX del GATT seguían siendo aplicables en términos generales, ya que estimaron que no existía conflicto entre las disposiciones del párrafo 1 del artículo XIX del GATT y las del párrafo 1 del artículo 2o. del Acuerdo sobre Salvaguardas. ${ }^{19}$

En el caso de Argentina, dicho país sostuvo que el requisito establecido en el artículo XIX según el cual las importaciones deben ser consecuencia de la evolución imprevista de las circunstancias no se encuentra en vigencia desde la entrada en vigor del Acuerdo sobre Salvaguardas de la OMC. En efecto, el Acuerdo sobre Salvaguardas, que interpreta al artículo XIX del GATT, no hace referencia en su artículo 2o. (condiciones para la aplicación de una medida de salvaguarda), ni en ningún otro artículo, a la necesidad de que el aumento de las importaciones deba ser el resultado de una "evolución imprevista de las circunstancias". El Acuerdo sobre Salvaguardas prevalece sobre el artículo XIX, y que en consecuencia no debe cumplir un requisito establecido en este artículo que no ha sido recogido en el Acuerdo sobre Salvaguardas. La Argentina argumentó que la no inclusión de este requisito en el Acuerdo sobre Salvaguardas, acuerdo multilateral destinado a "aclarar y reforzar las disciplinas del GATT de 1994 y concretamente las de su artículo XIX" para producir un "reajuste estructural" (como reza el preámbulo de dicho acuerdo), no puede considerarse como no intencional, ni como fruto de un olvido. Esa omisión debe interpretarse como resultado del "reajuste estructural", una intención deliberada de no incluir ese requisito del Acuerdo sobre Salvaguardas con el fin de posibilitar que esta herramienta pueda ser utilizada en los casos en que las importaciones de un producto cumplan las condiciones establecidas en el artículo 2o., aun cuando ese incremento de las importaciones no sea resultado de una evolución imprevista de las circunstancias, sino en general de "condiciones tales que causan o amenazan causar un daño grave". ${ }^{20}$

19 Véase el párrafo 7.39 del Informe.

20 Véanse párrafos 5.33 y 5.34 del Informe. 
El Grupo Especial señaló a este respecto ${ }^{21}$ que en el artículo 1o. del Acuerdo sobre Salvaguardas no se hace referencia a la aplicación del artículo XIX como tal. El artículo se refiere más bien a la aplicación de medidas de salvaguarda, que luego se definen como las medidas previstas en el artículo XIX. Sin embargo, en el artículo 11 se dice claramente que "tales medidas [de urgencia]" deben ser conformes a las disposiciones del artículo XIX "aplicadas de conformidad con el presente Acuerdo [sobre Salvaguardas]”. Lo anterior indica, según el Grupo Especial, que la aplicación de medidas de salvaguarda según el significado del artículo XIX requiere - a partir de la entrada en vigor del Acuerdo sobre Salvaguardas - la conformidad con los requisitos y condiciones de este último Acuerdo. Toda ejecución de las medidas de salvaguarda según el significado del artículo XIX supone la aplicación de las disposiciones del Acuerdo sobre Salvaguardas y, por consiguiente, el cumplimiento de las mismas. Es decir, las normas para imponer las medidas de salvaguarda previstas en el artículo XIX del GATT y las reglas para imponer las medidas de salvaguarda derivadas del Acuerdo sobre Salvaguardas deben leerse conjuntamente y han llegado a estar intrínsecamente vinculadas, si es que no son inseparables a partir de la entrada en vigor del Acuerdo sobre la OMC.

Si bien el Acuerdo sobre Salvaguardas no invalida ni reemplaza el artículo XIX, que permanece en vigor como parte del GATT, las condiciones originales contenidas en el artículo XIX deben leerse habida cuenta de las disposiciones específicas del Acuerdo sobre Salvaguardas que se negociaron ulteriormente y son mucho más específicas.

La cuestión entonces radica en determinar si el artículo XIX del GATT establece requisitos legales adicionales a los incluidos en el ASG. ${ }^{22}$ El párrafo 1, inciso a transcrito, contiene diversas hipótesis que deben presentarse en el caso concreto y desde luego acreditarse fehacien-

${ }^{21}$ Párrafos 8.55 y 8.56 del Informe.

22 Lee, Yong-Shik, "Destabilization of the Discipline on Safeguards? Inherent problems with continuing application of Article XIX after the settlement of the Agreement on Safeguards”, Journal of World Trade, Ginebra, Kluwer Law International, vol. 35, núm. 6, diciembre de 2001, p. 1237. 
temente para poder aplicar legítimamente, las medidas contenidas en el mismo precepto.

Para efectos de su mejor comprensión las consideramos en dos grupos:

1) Condiciones existentes que justifiquen la imposición de las medidas de escape o salvaguarda. Para ello deberá efectuarse una investigación cuidadosa por parte de las autoridades afectadas con base en elementos claros y sobre todos objetivos que justifique la medida protectora.

2) La imposición de la medida o de las acciones correctoras y protectoras que se decidan tomar y la sujeción a ello de ciertos parámetros y condiciones que las legitimen.

Los requisitos del primer grupo son:

a) Una evolución imprevista en las circunstancias. ${ }^{23}$

b) La existencia de una obligación de aplicar ciertas concesiones arancelarias a cargo de una parte contratante derivadas del "presente Acuerdo", esto es del GATT.

c) El incremento de las importaciones de un producto (obviamente del beneficiado con las preferencias concedidas), en cantidades tales que ocasionen o amenacen causar un daño grave a los productores nacionales de productos similares o directamente competidores.

d) El afectado podrá suspender total o parcialmente la obligación de referencia, modificarla o más aún retirarla.

e) Tal medida se establecerá sólo por un término y en la medida necesaria para reparar o prevenir el daño, salvo cuando se decida retirarla.

23 OMC- Los resultados de la Ronda Uruguay de Negociaciones Comerciales Multilaterales - Los textos Jurídicos, 2003. 


\section{Evolución imprevista de las circunstancias}

El término de "imprevisto" que contiene el texto del precepto legal no deja de tener sus complicaciones al consistir en que las circunstancias no fueron estimadas al otorgar la concesión pero que pudieron haberse considerado como un acontecimiento probable. Se trata en realidad de una percepción subjetiva pues un miembro pudo haber previsto unas circunstancias que otro miembro no logró percibir. ${ }^{24}$

Los comentarios que esta causa para aplicar el artículo XIX ha formulado la $\mathrm{OMC}^{25}$ nos llevan a enfatizar tal diferenciación derivados del primer caso verdaderamente relevante que se presentó sobre el particular cuyas partes fueron los Estados Unidos de América como demandada y la entonces Checoslovaquia como actora en 1950 así como Austria, Francia, Italia y Gran Bretaña como países afectados.

Dicho caso se ha convertido en clásico en la materia pues el Grupo de Trabajo conformado de acuerdo a las normas del GATT aplicables, concretamente el artículo XXIII.2, definió y precisó algunos conceptos legales.

Así se refirió al tema de los acontecimientos imprevistos de la siguiente manera:

That the term "unforeseen development" should be interpreted to mean developments occurring after the negotiation of the relevant tariff concession which it would not be reasonable to expect that the negotiators of the country making the concession could and should have foreseen at the time when the concession was negotiated. ${ }^{26}$

Resulta por demás interesante no sólo lo anterior sino también el hecho de que aún si el acontecimiento resulta difícil de prever, menos posible será vislumbrar los efectos económicos que se derivan de los mismos.

${ }^{24}$ Lee, Yong-Shik, “Critical issues...”, cit., p. 135.

25 WTO, Guide to GATT Law and Practice, Geneva, 1995, p. 518.

26 "Withdrawal by the United States of a Tariff Concession under Article XIX of the General Agreement” GATT/CP/106 22, octubre de 1951. 
Un matiz que ha sido sugerido es que el cambio de las circunstancias constituya algo más que un cambio general del orden económico ya que resulta claro que por el solo hecho de abatir los aranceles devendrá un perjuicio económico al productor doméstico.

La discusión sobre la aplicabilidad del artículo XIX del GATT en este punto conjuntamente con el ASG cobra gran relevancia si consideramos que la evolución imprevista de las circunstancias es un requisito no incluido en el artículo 2.1 del ASG que establece que un miembro sólo podrá aplicar una medida de salvaguarda a un producto si dicho miembro ha determinado que las importaciones de ese producto en su territorio han aumentado en tal cantidad, en términos absolutos o en relación con la producción nacional, y se realizan en condiciones tales que causan o amenazan causar un daño grave a la rama de producción nacional que produce productos similares o directamente competidores.

En el caso Estados Unidos-Medida de salvaguarda contra las importaciones de cordero fresco, refrigerado o congelado procedentes de Nueva Zelandia, ${ }^{27}$ se determinó que conforme a la resolución del Órgano de Apelación en el citado caso de Corea, la demostración de la existencia de una "evolución imprevista de las circunstancias" sí constituye un requisito jurídico ${ }^{28}$ ya que toda medida de salvaguarda impuesta después de la entrada en vigor del Acuerdo sobre la OMC debe ajustarse tanto a las disposiciones del Acuerdo sobre Salvaguardas como a las del artículo XIX del GATT de 1994. ${ }^{29}$

Diversos autores no concuerdan con la anterior interpretación al señalar que la referencia general al artículo XIX del GATT hecha en el artículo 1o. del ASG no implica que todas las disposiciones del XIX se mantienen en vigor. Máxime cuando el artículo 11.1 del ASG es claro al señalar que ningún miembro adoptará ni tratará de adoptar medidas de urgencia sobre la importación de productos determinados a tenor de lo dispuesto en el artículo XIX del GATT de 1994 a menos que tales medidas sean conformes a las disposiciones de dicho artículo aplicadas de conformidad con el ASG. Lee considera que "revivir" el requisito de

\footnotetext{
WT/DS177/R,WT/DS178/R 21 de diciembre de 2000, Informe del Grupo Especial.

Párrafo 7.19.

29 WT/DS98/AB/R del 14 de diciembre de 1999, párrafo 77.
} 
la imprevisibilidad de las circunstancias crea un riesgo innecesario de desestabilización de la disciplina sobre salvaguardas. ${ }^{30}$

Inclusive se señala por la doctrina que una de las características principales del ASG es precisamente la no exigencia de evolución imprevista de las circunstancias ni la relación con las obligaciones del GATT. ${ }^{31}$

\section{Una obligación legal de establecer ciertas preferencias arancelarias}

La intención del párrafo $b$ del artículo XIX es que los acuerdos comerciales preferenciales se promuevan y no se pongan en riesgo debido a concesiones hechas en las negociaciones multilaterales.

Aparentemente es simple demostrar la hipótesis de la existencia de una obligación previa acorde con el GATT pues bastará acreditar la existencia del acuerdo correspondiente y su cumplimento al modificar los aranceles.

No así el vínculo de causalidad entre tal hecho, unido además al incremento de las importaciones y los efectos negativos, más el cambio de circunstancias que concurren al mismo tiempo.

¿Hasta dónde puede darse una simple coincidencia de factores y hasta dónde se podrá atribuir sólo a uno de ellos, la razón del efecto negativo?

Por otra parte, si un país sufre un daño o su amenaza por el incremento súbito de importaciones que afectan a sus productos mas no existe un acuerdo preferencial previo ¿el afectado no podrá acudir al artículo XIX?

Dado que la existencia del ASG no abroga el texto del artículo XIX sino por lo contrario lo aclara y precisa, se podría derivar de lo dicho, que ya no se exige el requisito de la existencia de una preferencia arancelaria previa y su aprovechamiento por parte del beneficiario como

30 Lee, Yong-Shik, “Destabilization...”, cit., pp. 1239-1242.

31 Bronckers, Marco C.E.J., "WTO implementation in the European Community. Antidumping, Safeguards and Intellectual Property", Journal of World Trade, Ginebra, Kluwer Law International, vol. 29, núm. 5, octubre de 1995, p. 85. Una postura distinta en Mueller, Felix, "Is the General Agreement on Tariffs and Trade Article XIX «Unforseen Developments Clause» still effective under the Agreement on Safeguards?", Journal of World Trade, Ginebra, Kluwer Law International, vol. 37, núm. 6, diciembre de 2003. 
aparece en el texto del artículo XIX en su párrafo 1 , inciso $b .^{32}$ Sin embargo, al no haber un conflicto "formal" entre ambas disposiciones y partiendo de que la "evolución imprevista" sí se considera vigente, no hay base para considerar que el citado párrafo 1 , inciso $b$ del artículo XIX no continúa vigente, lo cual tiene consecuencias importantes ya que las disposiciones procesales contenidas en el ASG no están diseñadas para la imposición de medidas de salvaguarda a petición del país afectado. $^{33}$

\section{El incremento en las importaciones de un producto en un volumen tal} o en términos absolutos en relación con la producción nacional del bien similar o directamente competitivo

Originalmente no se califica lo relativo al hecho de que el incremento de las importaciones deban considerarse con referencia a algún factor de la producción doméstica. El país afectado podrá a su criterio, determinar si será con base en la producción doméstica correspondiente o en términos absolutos.

En ambos casos hay un elemento presente que juega un papel definitivo como es recargar el peso en el volumen de las importaciones más que en su valor.

Una de las razones para subrayar esta distinción estriba en que el factor valor de los bienes se puede ver afectado por variaciones cambiarias y esto distorsiona el requisito exigido.

Al evaluar el susodicho incremento necesariamente será pertinente considerar un plazo para medirlo. ${ }^{34}$

32 La eliminación de este requisito se hizo en concordancia con lo que establece el artículo 201 de la Trade Act. of 1974 (19 U. S. C. 2251 - 2253 de los Estados Unidos).

33 Véase Lee, Yong-Shik, “Destabilization...”, cit., p. 1244.

34 Se han planteado diversos criterios; en algunas casos como sucede con la ley mexicana, se previene en el artículo 72 del Reglamento de la Ley de Comercio Exterior de 1993 que el “... crecimiento considerable de las importaciones totales...” deberá haber sucedido en un periodo relativamente corto. Curiosamente la propia ley no se pronuncia sobre el plazo sino solamente enfatizó el incremento de las importaciones y el daño o su amenaza (artículo 45). Véase Ley de Comercio Exterior, consultable en http://www.ordenjuridi co.gob.mx/Federal/ Combo/L-21.pdf. 
Las disposiciones estadounidenses han permitido la utilización en la práctica y en general de un término de cinco años ${ }^{35}$ sin perjuicio de que en circunstancias especiales sea modificado a más corto o mayor. ${ }^{36}$

En cuanto al texto del artículo XIX, para nada se ocupa del plazo sino basta que se presente el aumento de las importaciones. ${ }^{37}$ Confirma lo anterior el hecho de que en diversas ocasiones en que se tuvo la posibilidad de revisar o precisar el plazo con motivo de salvaguardas estimada al negociar el acceso al GATT de varios países del área comunista como fueron Polonia, Rumania y Hungría en los sesenta y setenta, no se hizo.

En el caso de China que fue mucho más complejo y que requirió de un Protocolo de Accesión negociado con mucho detalle (11 de noviembre de 1991), encontramos que solamente se hace mención textual del incremento en las importaciones sin calificar el término en que éstas ocurran, tal como lo encontramos en el artículo XIX.

Tampoco en los borradores que antecedieron al Protocolo en cuestión del 20 de diciembre de 1994 y del 6 de marzo de 1997, se ocuparon del término mas sí lo menciona este último al consignar que las importaciones se hagan en un porcentaje desproporcionado en relación con el incremento total de las importaciones "... during the representation period provided for in the Agreement on Safeguards...”. 38

En conclusión, podemos derivar que en cuanto al periodo en que se dé el incremento de la importación, no está restringido a un plazo rígido sino son otros los requisitos y condiciones que deben ser satisfechos a la luz de la mayor parte de las legislaciones existentes. ${ }^{39}$

35 Secc. 201 Relief - 19 CFR - Part 206 - 29 - August 1988 Regulatory Requirements.

36 Algunos casos norteamericanos ilustran estos puntos: Birch Playwood Doors Kins USITIC, Pub 743, octubre de 1975. Stainless Steel Table Flatware USITIC Pub 739, 1976 (periodo de 8 años) - Sugar USITIC Pub 207, 1977 - Stainless Steel and Alloy tool Steel - USITICPub 156, 1976 (11 años).

37 "The Uruguay Round Agreement on Safeguards resolves the matter conclusively for GATT purposes in paragraph 2, which indicate that an increase in the market share of imports will suffice”, en Jackson, John H. et al., Legal Problems of International Economic Relations, St. Paul, Minnesota, West Publishing, 1995, p. 612.

38 Citado y comentado por Spadi, Fabio, "Discriminatory Safeguards in the light of the Adminission of the People's Republic of China to the World Trade Organization”, Journal of International Economic Law, vol, 5, núm. 2, junio de 2002, p. 432.

39 El hecho de que el Grupo de Trabajo en el clásico caso de las importaciones de sombreros de piel, haya consignado el incremento grande y rápido de las importaciones no significa que deban ser en corto plazo "Womes fur felt hats and bodies" - GATT/CP/106, 1950 - 1956. 
Sin embargo, las legislaciones nacionales marcan una tendencia en que sea lo más cercano al inicio de las investigaciones pese a que un plazo mayor mostraría un incremento lógico de las mismas y ésta ha sido confirmada en varios casos ventilados ante la OMC por el Tribunal de Apelación, sobre todo cuando se trata de una amenaza de daño.

El Informe del Órgano de Apelación en el caso Argentina-Medidas de salvaguarda impuestas a las importaciones de calzado ${ }^{40}$ estableció que el aumento de las importaciones debía haber sido "imprevisto" o "inesperado". Asimismo, señaló que la expresión "han aumentado en tal cantidad" que se emplea en el párrafo 1 del artículo 2o. del ASG y en el párrafo 1 $a$ del artículo XIX del GATT de 1994 es importante tratándose de esta determinación. Para el Órgano de Apelación la determinación de si se ha cumplido el requisito de las importaciones que "han aumentado en tal cantidad" no es una determinación puramente matemática o técnica. En otras palabras, no es suficiente que una investigación demuestre simplemente que las importaciones de este año han sido mayores a las del año pasado —o a las de hace cinco años- No basta cualquier aumento en la cantidad de las importaciones. Para que se cumpla el requisito a la aplicación de una medida de salvaguardia, las importaciones deben haber aumentado "en tal cantidad" que causen o amenacen causar un daño grave a la rama de producción nacional. Se requiere que el aumento de las importaciones haya sido lo bastante reciente, lo bastante súbito, lo bastante agudo y lo bastante importante, tanto cuantitativa como cualitativamente, para causar o amenazar con causar un "daño grave".

\section{Que causen o amenacen causar un daño grave a la producción nacional del bien similar o directamente competidores}

Entre los supuestos que están presentes sin ninguna duda, en las pesquisas que el Estado realice para definir medidas en contra de las importaciones, está siempre la presencia de una afectación negativa a la industria local que se materializa a través del daño o de su amenaza.

$40 \mathrm{WT} / \mathrm{DS} 121 / \mathrm{AB} / \mathrm{R}$ de 14 de diciembre de 1999, Informe del órgano de apelación, párrafo 131 . 
Para determinar si existe será conveniente tomar en cuenta que el daño con su amenaza se encuentra estrechamente ligado con otros elementos como son el incremento de las importaciones ya comentado y la relación de causalidad; factores el primero meramente estadístico y el segundo lógico, de comprobación compleja y más aún si la disposición legal aplicable le reviste de calificativos como es el caso.

En efecto, tanto en la doctrina como en el derecho positivo, se establecen distinciones entre los grados del daño y se habla del material para el caso de las prácticas desleales de comercio, y de grave para las prácticas leales: curiosa paradoja pues el segundo es más difícil de comprobar dada su complejidad.

En algunas legislaciones inclusive se consideran otros grados del daño como el sustantivo o el serio, pero en el GATT solamente se consideran los primeramente anotados.

Para hacer menos complicado el tema, el ASG formula algunos criterios y elementos objetivos que deberán acreditarse para demostrar el daño o su amenaza. El artículo 4.2 a nos ilumina sobre lo que significa en el artículo XIX 1 a, la expresión “... en condición tales...” aplicada a las importaciones crecientes que dan pie a que se produzca el daño.

Así previene que “... las autoridades competentes evaluarán todos los factores pertinentes de carácter objetivo y cuantificable que tengan relación con la situación de esta rama de producción...” enfatizando lo siguiente:

a) El ritmo y la cuantía del aumento de las importaciones del producto de que se trata en términos absolutos y relativos.

b) La parte del mercado interno absorbida por las importaciones en aumento.

c) Los cambios en el nivel de ventas.

d) La producción, la productividad, la utilización de la capacidad, el empleo.

e) Las ganancias y las pérdidas.

Es de mencionarse que el texto de los incisos $a$ y $b$ del párrafo 2 del artículo 4o. subrayan en dos ocasiones que las pruebas y factores a considerar deberán ser objetivos. 
No está claro si el artículo 4.2 requiere que todos los factores señalados sean considerados, si bien el Grupo Especial en el caso Corea Medida de salvaguarda definitiva impuesta a las importaciones de determinados productos lácteos ${ }^{41}$ determinó que sí. ${ }^{42}$

Solamente si el resultado de la investigación llevada a cabo acredita la existencia real del daño o su amenaza, el miembro afectado podrá aplicar la medida de salvaguarda, debiendo observar además los requisitos legales propios a toda investigación según advierte el artículo 3o., párrafo 1 y 2 del ASG.

No bastará agotar la señalada investigación sino la demostración de la existencia del nexo de causalidad directo entre el incremento de las importaciones y el daño o su amenaza.

Se advierte que la presencia de otros factores distintos a la importación de los bienes en cuestión que estén presentes al considerar el daño a la producción doméstica, provocará que se excluyan como causantes del mismo (artículo 4.2.b).

Al llevar a cabo el proceso de investigación, decíamos que se deberán acreditar la existencia de una serie de hipótesis para que nazca el derecho del miembro afectado para tomar diversas medidas que suspendan o disminuyan la importancia de un bien determinado.

Tanto el artículo XIX del GATT como el ASG en sus artículos 2o., 3o. y 4o. establecen los requisitos que deben satisfacerse, para que dichas medidas sean legítimas.

De su lectura desprendemos que son los mismos con las excepciones ya referidas relativas a la existencia previa de las concesiones arancelaria concedidas que menciona el párrafo 1 a del artículo XIX y a la evolución imprevista, pues el artículo 2o. del ASG sólo menciona el aumento de las importaciones en ciertas circunstancias.

En los preceptos mencionados del ASG y particularmente en el artículo 2o. cuyo texto reproduce algunas expresiones, a la letra del citado ar-

${ }^{41}$ WT/DS98/R, 21 de junio de 1999, Informe del Grupo Especial, párrafo 7.55.

42 Lee, Yong-Shik, "Review of the first WTO Panel Case on the Agreement on Safeguards. Korea-Definitive measure on imports of certain daily products and its implications for the application of the Agreement", Journal of World Trade, Ginebra, Kluwer Law International, vol. 33, núm. 6, diciembre de 1999, p. 36. 
tículo XIX no aparece la mención de las obligaciones citadas ni tampoco en los siguientes preceptos.

Si recordamos que el ASG en su parte declarativa concretamente en el párrafo segundo, advierte que se atiende a “... la necesidad de aclarar y reforzar las disciplinas del GATT 1994, y concretamente las de su artículo XIX", debemos entender que ambos ordenamientos constituyen uno solo y en caso de duda deberá prevalecer el segundo por ser posterior.

No estimamos que se trate de una contradicción pues son textos de diferentes épocas por lo que simplemente se actualizó el primero aplicable a las salvaguardas, para facilitar su utilización por los miembros que lo requiriesen. En concordancia con nuestra opinión tenemos que:

Las Comunidades Europeas sostienen que hay cuatro relaciones posibles entre una disposición del GATT 1994 y un Acuerdo contenido en el Anexo 1A del Acuerdo de Marrakech... un conflicto entre las disposiciones de los dos textos; una duplicación de disposiciones de los textos; una excensión expresa en un Acuerdo del Anexo 1A del Acuerdo de la OMC que permite una infracción al GATT 1994; y la complementariedad de disposiciones. Las Comunidades Europeas alegan que la cuarta opción... describe la relación que existe entre el párrafo 1A del Artículo XIX y el párrafo 1 del artículo II del Acuerdo sobre Salvaguardas... ${ }^{43}$

Así podemos derivar que ya no será necesario presumir la existencia de una obligación a cargo de uno de ellos y a favor de otro, el beneficiario.

La razón para suprimir la referencia a las obligaciones fundadas en el GATT, se debió a la falta de definición del concepto, pues tal como aparece cabe suponer que no sólo será aplicable cuando existan fracciones arancelarias y aranceles desgravados a través de las listas establecidas sino en otros posibles preceptos como en el artículo XI del GATT.

${ }_{43} \mathrm{WT} / \mathrm{DS} 121 / \mathrm{AB} / \mathrm{R}-14$ de diciembre de 1999, párrafo 41. 


\section{La amenaza del daño}

El apartado $b$ del párrafo 1 del artículo 4o. del ASG nos precisa que: "La determinación de la existencia de una amenaza de daño grave se basará en hechos y no simplemente en alegaciones, conjeturas o posibilidades remotas".

No resultando suficiente esta mención habrá que acudir a otros índices que nos auxilien para saber qué elementos deberán ser tomados en cuenta para considerar que tal amenaza existe.

El concepto de daño y su amenaza deben revestir el carácter de "grave" que no es igual al de "importante" que se exige en el caso de las prácticas desleales como son el dumping y los subsidios. Difícilmente podemos citar otros factores a estimar diversos entre uno y otro caso sino solamente el énfasis está en la graduación del mismo. ${ }^{44}$

Es conveniente traer a colación la reflexión que efectuara el Órgano de Apelación sobre el particular en el caso Argentina-medidas de salvaguarda impuestas a la importaciones de calzado 45 , en cuanto a que: "Una evaluación de cada uno de los factores enumerados no tiene porque demostrar necesariamente que cada uno de ellos está disminuyendo".

La autoridad examinadora deberá constatar la "clara inminencia" del daño grave. Tal como se afirmó por el Grupo de Apelación en el caso anteriormente comentado de "Estados Unidos, medidas de salvaguardia respecto a las importaciones de carne de cordero fresca... procedente de Nueva Zelandia y Australia”, ${ }^{46}$ “... esto requiere un alto grado de probabilidad de que el daño grave se materialice en un futuro muy próximo...", la determinación de la existencia de una amenaza está “orientado hacia el futuro... la aparición de los hechos futuros nunca se puede probar definitivamente basándose en los hechos... lo que en definitiva requiere un cierto grado de conjetura...”.

$44 \mathrm{WT} / \mathrm{DS} 177 / \mathrm{AB} / \mathrm{RWT} / \mathrm{DS} 178 / \mathrm{AB} / \mathrm{R}$ - 1 de mayo de 2001 op. cit. supra, párrafo 124.

$45 \mathrm{WT} / \mathrm{DS} 121 / \mathrm{AB} / \mathrm{R}$ - 14 de diciembre de 1999, párrafo 132-139.

46 Op. cit., párrafos 136-139. 


\section{La rama de producción nacional}

Al importarse un bien sea industrial o agrícola, se puede afectar a uno igual, similar o directamente competidor fabricado o producido en el país importador. Por ello el artículo 4.1 a contiene la premisa de que se ocasione un daño grave a una rama de la producción nacional acotando la referencia que el artículo XIX establece en el párrafo 1 a que nos habla de "... productos nacionales de productos similares o directamente competidores...”.

Por rama de producción nacional nos indica el párrafo $1 c$ del citado artículo 4o. que se entenderá el conjunto de productores del bien, que operan dentro del territorio del miembro afectado. Por productores debemos entender los que crean, originan, fabrican o elaboran algo o dicho en otros términos, los que hacen que algo exista.

Siendo esta descripción general, debemos acotarla conforme al texto ya invocado, sólo a quienes producen bienes similares o directamente competidores quedando lógicamente fuera de consideración quienes no reúnan esta condición.

Todo ello conduce a que de tomarse una medida de salvaguarda sea únicamente referida a un producto concreto. En la práctica de la $\mathrm{OMC}$ se ha enfatizado que las autoridades nacionales, más allá de exigir los requisitos que a su entender sean procedentes, tendrán necesariamente que verificar si los importados son similares o directamente competidores, de los nacionales.

Podíamos añadir que en el proceso definitivo de lo que se debe entender por industria doméstica, cabría sugerir la revisión de las facilidades existentes en la manufactura del bien estudiado, al proceso de fabricación del mercado propio o natural del mismo, la posibilidad del intercambio de los productos en cuestión y otros elementos informativos que permitan conocer la industria en cuestión a efectos de ubicarla como la afectada por las importaciones.

\section{La causalidad}

En cuanto a la exigencia del vínculo de causalidad entre el incremento de las importaciones y la existencia de las obligaciones consignadas, su 
acreditación es compleja y numerosas peticiones llevadas a cabo por industrias norteamericanas no prosperaron por existir tal causal, lo que llevó a suprimir este requisito en la ley norteamericana y con ello a su ausencia en el ASG elaborado casi 20 años después. ${ }^{47}$

En síntesis, concluimos sobre este particular que la desaparición por elemental congruencia de la obligación de otorgar ciertas concesiones arancelarias y la necesidad de acreditar el nexo de causalidad entre las mismas así como demostrar adicionalmente dicho vínculo con las importaciones, ya desapareció.

Continuando con el análisis del requisito del daño ocasionado a la industria doméstica o de su amenaza, debemos separar dos elementos que se presentan en el tema: la repercusión económica del efecto negativo, y la posibilidad de probarlo objetivamente, tal como establece el artículo 4.2. $a$ y $b$ del ASG.

La autoridad nacional que realice la investigación que eventualmente lleve a la decisión de imponer una medida de salvaguarda o escape, ordinariamente no tiene el carácter jurisdiccional sino administrativo, debe examinar técnicamente los elementos probatorios que se pongan a su disposición y así poder arribar a una conclusión que será emitir un juicio lógico fundado para proceder legítimamente.

El artículo XIX no proporciona mayores elementos que nos guíen, en cambio el artículo 4.1. a nos dice que deberá consistir en “... un menoscabo significativo de la situación de una rama de producción nacional...”.

En su examen la autoridad revisará entre otros los factores enumerados en el párrafo 2 del citado precepto que ya hemos mencionado anteriormente.

Cabe señalar que esta tarea es similar a la que se debe llevar a cabo en los casos de prácticas desleales de comercio mas no así los efectos del daño pues en la pesquisa que comentamos deberá ser "grave”; en cambio en las primeras bastará que sea importante.

El mercado interno será el que refleje y proporcione los elementos de juicio ya que la pérdida que sufra el productor doméstico y la penetración al mismo del producto importado señalarán claramente su efecto negativo a la industria nacional.

47 La Trade Act. of 1974 que reformó numerosas disposiciones comerciales incluye la correspondiente a la Secc. 201 (Title IV, Section 406. Pub L. núm. 93 - 618, 88 Stat. 2062 (1975). 
Igual sucederá si estimamos que la producción doméstica disminuye a consecuencia de una pérdida en sus ventas, lo que a su vez se reflejará en el aumento de la desocupación laboral y por ende de la capacidad productiva de la planta industrial o agrícola.

Todos estos factores, como advertimos, son marcadamente económicos y aparecen en las estadísticas oficiales y privadas mas no serán suficientes si no existe una vinculación directa de causa (las importaciones) y el efecto (el daño o su amenaza).

Se deben discriminar con precisión los efectos producidos por el incremento de las importaciones, de aquellos que tienen otras causas distintas a este factor externo como pueden ser la contracción del mercado interno por razones políticas, sociales o simplemente por caídas de la producción nacional.

Si esto sucediere deberá aplicarse lo que previene el párrafo 2, en la parte última del artículo 4o. que reza:

Cuando haya otros factores, distintos del aumento de las importaciones que al mismo tiempo cause daño a la rama de producción nacional, este daño no se atribuirá al aumento de las importaciones.

El ASG precisa en su artículo 4.2. b que:

No se efectuará la determinación a que se refiere el apartado a) del presente párrafo a menos que la investigación demuestre... la existencia de una relación de causalidad entre el aumento de las importaciones del producto que se trate y el daño grave...

La necesidad de acreditar que existe una vinculación clara entre en incremento de las importaciones y el daño amenazado y provocado, es ineludible.

Tomaremos la siguiente afirmación del órgano de apelación en el caso Estados Unidos-Medida de salvaguarda contra las importaciones de cordero fresco, refrigerado o congelado procedentes de Nueva Zelandia ${ }^{48}$ que es contundente:

$48 \mathrm{WT} / \mathrm{DS} 177 / \mathrm{AB} / \mathrm{R}, \mathrm{WT} / \mathrm{DS} 178 / \mathrm{AB} / \mathrm{R}$ del 1o. de mayo de 2001, Informe del órgano de apelación, párrafo 179 . 
En una situación en la que varios factores causen daño "al mismo tiempo", sólo puede formularse una determinación definitiva acerca de los efectos perjudiciales del aumento de las importaciones si se distinguen y separan los efectos perjudiciales causados por la totalidad de los diversos factores causales. De no ser así, cualquier conclusión basada exclusivamente en una evaluación de uno solo de los factores causales — el aumento de las importaciones - carecería de una base sólida, porque se presumiría que los demás factores causales no causaban el daño que se habría imputado al aumento de las importaciones. La prescripción del párrafo 2 b) del artículo 4 relativa a la no atribución excluye esa presunción y exige, por el contrario, que las autoridades competentes evalúen apropiadamente los efectos perjudiciales de otros factores, a fin de que esos efectos puedan separarse de los efectos perjudiciales del aumento de las importaciones. De esta forma, la determinación definitiva se basa, adecuadamente, en la relación auténtica y sustancial de causa a efecto entre el aumento de las importaciones y el daño grave.

Este tema fue abordado en el caso Estados Unidos-Medidas de Salvaguardia Definitivas Impuestas a las Importaciones de Gluten de Trigo procedentes de las Comunidades Europeas. ${ }^{49}$

\section{Producto "directamente competidor"}

La expresión "productos similares o directamente competidores" aparece en los artículos XIX. 1. a y b del GATT y en el 1o. 1 y 4o. $1 a, b$, y 2o. párrafos del ASG.

En ambos textos no se dan mayores datos para identificarlo sino solamente se mencionan como si fueran equivalentes.

En el caso Chile-Impuestos a las bebidas alcohólicas, ${ }^{50}$ el órgano de apelación manejó indistintamente el concepto de "directamente competidores o directamente sustituibles" e invocó otro anterior, el de "Japónbebidas alcohólicas" ${ }^{51}$ en el que el mismo órgano colegiado usó ambos

49 WT/DS166/AB/R del 22 de diciembre de 2000. Informe del órgano de apelación, párrafos 33 a 44.

$50 \mathrm{WT} / \mathrm{DS} / 87 / \mathrm{AB} / \mathrm{R}, \mathrm{WT} / \mathrm{DS} / 110 / \mathrm{AB} / \mathrm{R}$ del 13 de diciembre de 1999. Informe del órgano de apelación, párrafos 47, 48 y 49.

${ }^{51} \mathrm{WT} / \mathrm{DS} / 8 / \mathrm{AB} / \mathrm{R}, \mathrm{WT} / \mathrm{DS} / 10 / \mathrm{AB} / \mathrm{R}$ y WT/DS/11/AB/R de 1o. de noviembre de 1996. 
conceptos en la misma manera, mas en su reporte de Recomendaciones, no ofrece ninguna diferencia.

Ante tal ausencia de elementos, cabe atender la sugerencia del profesor Raj Bhala en el sentido de que deberán analizarse los productos con gran cuidado y poder determinar si existe tal diferencia que permita resolver la duda aplicando el criterio de que prevalecerán las similitudes a las diferencias. ${ }^{52}$

\section{CRISIS ECONÓMICA Y SALVAGUARDAS}

La crisis económica mundial ha tenido como consecuencia la contracción de los mercados externos en la demanda de los productos fabricados localmente, ocasionando excedentes en la producción nacional derivada de la caída en la demanda tanto nacional como internacional y la cancelación de operaciones previamente pactadas.

Dichos excedentes de producción se verán reducidos mediante la disminución en los niveles de producción, las posibles ventas internas y la colocación de los mismos en los mercados internacionales que se mantengan abiertos ante y pese a la crisis. ${ }^{53}$

Inclusive, la aplicación de medidas proteccionistas puede provocar la desviación de los flujos de mercancías de sus mercados naturales a nuevos objetivos de venta, provocando a su vez la adopción de nuevas medidas en esos mercados y una escalada en el nivel de protección a fin de prevenir la desviación señalada, como sucedió con la aplicación de la medida de salvaguarda en contra del acero por los Estados Unidos de América. ${ }^{54}$

52 Bahla, Raj y Kennedy, Kevin, op. cit., p. 911.

53 Caso de México con el DECRETO por el que se modifica la Tarifa de la Ley de los Impuestos Generales de Importación y de Exportación publicado en el Diario Oficial de la Federación el 24 de diciembre de 2008 en donde el gobierno mexicano justificó su apertura arancelaria se debe a la necesidad de "renovar su compromiso con un comercio exterior cada vez más libre que fortalezca el poder adquisitivo de las familias y la competitividad de las empresas, que conlleve a privilegiar la certidumbre jurídica, la equidad, la eficiencia, la transparencia, así como la competencia y libre concurrencia en esta materia”.

54 El 1o. de noviembre de 2002, el Taipei Chino solicitó la celebración de consultas con los Estados Unidos con respecto a las medidas de salvaguardia impuestas por los Estados Unidos a las importaciones de determinados productos de acero. Actualmente estas medidas están 
Las crisis económicas históricamente han resultado en un incremento del proteccionismo, de ahí que la observancia de la disciplina en materia de salvaguardas es de gran importancia en estos momentos. ${ }^{55}$

Se señala que la respuesta ante los cambios en el mercado internacional debe ser el ajuste y no el proteccionismo, ${ }^{56}$ sin embargo, consideramos que las medidas de salvaguarda correctamente aplicadas son necesarias para permitir precisamente el ajuste y la recuperación de las industrias nacionales.

La recuperación de las corrientes del comercio mundial es un componente vital en el marco más amplio de recuperación de la economía internacional para el logro de un crecimiento sostenible. ${ }^{57}$

La reciente disminución en los volúmenes de comercio es atribuible a las fuerzas de recesión y al congelamiento en los mercados financieros, como consecuencia se da el alto precio de la financiación del comercio en los mercados privados, tanto para las transacciones a corto plazo como para los bienes de capital, servicios y proyectos de infraestructura que normalmente son objeto de créditos a la exportación. Estos acontecimientos, a su vez, podrían reducir aún más los flujos de comercio y la financiación de las exportaciones, especialmente para los mercados emergentes y los países en desarrollo.

Si bien los flujos comerciales de los países del G7 cayeron drásticamente en el último cuarto de 2008, información correspondiente a los primeros dos meses de 2009 indica una disminución en el ritmo de la

siendo examinadas por el Grupo Especial que se ocupa de los asuntos conjuntos WT/DS248, WT/DS249, WT/DS251, WT/DS252, WT/DS253, WT/DS254, WT/DS258, WT/DS259. Véase Lee, Yong-Shik, "Safeguard Measures: why are they not applied consistently with the rules. Lessons for competent national authorities and proposal for the modification of the rules on safeguards”, Journal of World Trade, Ginebra, Kluwer Law International, vol. 36, núm. 4, agosto de 2002, p. 665-667; id., "Test of multilateralism in international trade: U.S. Steel Safeguards”, Northwestern Journal of International Law \& Business, Estados Unidos, vol. 25, núm. 1 , Otoño de 2004.

55 Mueller, Felix, op.cit., p. 1121.

56 Ibidem, p. 1151.

57 Véase el documento de la OCDE titulado La crisis financiera global y créditos a la exportación fechado en París el 22 de abril de 2009. En http://www.coparmex.org.mx/conteni dos/internacional / newsletter/anexos / 2009/junio/Crisis\%20financiera\%20global\%20y\%20cr\% C3\%A9ditos\%20a\%201a\%20exportaci\%C3\%B3n.pdf. Consultado el 5 de septiembre de 2011. 
tasa de reducción del comercio. Se tienen datos de un ligero incremento en las exportaciones en el mes de febrero. ${ }^{58}$

En este sentido, la utilización de medidas de salvaguarda podría incrementarse como consecuencia de un posible aumento en las exportaciones de bienes en condiciones leales de comercio a los mercados internacionales.

Conforme a estadísticas publicadas por la OMC, ${ }^{59}$ entre el 29 de marzo de 1995 y el 31 de octubre de 2010 se iniciaron 216 investigaciones y se impusieron 101 medidas en materia de salvaguardas, de ahí la importancia de la correcta interpretación de las disposiciones multilaterales aplicables. ${ }^{60}$

Cabe destacar que durante el periodo de manifestación de la crisis que va del 1o. de enero al 12 de noviembre de 2008 se iniciaron cinco investigaciones sobre salvaguardas. Entre noviembre de 2008 y octubre de 2010 las investigaciones aumentaron sustancialmente: en 2009 se iniciaron 25 y en 2010 lo fueron 18, clara muestra de una reacción ante el entorno económico.

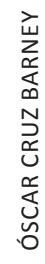

Las notificaciones de nuevas investigaciones iniciadas desde 1995 a la fecha son, por país:

- Argentina (6)

- Australia (2)

- Brasil (3)

- Bulgaria (6)

- Canadá (3)

- Chile (12)

- China (1)

- Colombia (3)

- Costa Rica (1)

- Croacia (1)

58 OECD International Trade Statistics, Trade flows collapse in Q4 2008 but signs of falls easing in early 2009, 30 de abril de 2009, en http://www.oecd.org/dataoecd/29/36/42668007.pdf. Consultado el 5 de septiembre de 2011.

59 http://www.wto.org/spanish/tratop_s/safeg_s/safeg_s.htm\#statistics. Consultado el 5 de septiembre de 2011.

${ }^{60}$ Lee, Yong-Shik, “Review...", op. cit., p. 27. 
- Ecuador (8)

- Egipto (4)

- El Salvador (3)

- Eslovenia (1)

- Estados Unidos (10)

- Estonia (1)

- Filipinas (9)

- Hungría (3)

- India (26)

- Indonesia (12)

- Israel (1)

- Jamaica (1)

- Japón (1)

- Jordania (15)

- Kirguistán (3)

- Latvia (2)

- Lituania (1)

- Marruecos (5)

- México (2)

- Moldavia (2)

- Pakistán (1)

- Panamá (1)

- Perú (2)

- Polonia (5)

- República Checa (9)

- República de Corea (4)

- República Dominicana (5)

- República Eslovaca (3)

- Sudáfrica (1)

- Túnez (2)

- Turquía (15)

- Ucrania (8)

- Unión Europea (5)

- Venezuela (6)

- Vietnam (1) 
Mientras que las cinco investigaciones iniciadas durante el periodo que corre del 1o. de enero al 12 de noviembre de 2008 correspondieron a Brasil, Egipto, Indonesia, Filipinas y Turquía, las 43 iniciadas entre 2009 y 2010 en plena crisis económica fueron de Chile (1), Croacia (1), República Dominicana (5), Ecuador (1), Filipinas (1), Unión Europea (1), La India (10), Indonesia (7), Israel (1), Jordania (1), Kirguistán (3), México (1), Marruecos (2), Perú (1), Turquía (1), Ucrania (5) y Vietnam (1).

Por lo que respecta a la aplicación de medidas de salvaguarda definitivas, durante el periodo comprendido entre el 1o. de enero y el 12 de noviembre de 2008 se impusieron seis nuevas medidas. El número de medidas definitivas anteriores a ese periodo alcanzó el punto máximo en 2003 (15) y posteriormente se había mantenido en unos niveles relativamente bajos. Las seis nuevas medidas impuestas durante el periodo del 1o. de enero al 12 de noviembre de 2008 corresponden a Turquía (cuatro), Egipto y Ucrania.

Entre 2009 y 2010 se impusieron 12 medidas de salvaguarda por los siguientes países: Croacia (1), República Dominicana (1), La India (3), Indonesia (2), Jordania (1), Kirguistán (1), Filipinas (1), Turquía (1) y Ucrania (1).

Las secciones del Sistema Armonizado que han sido con mayor frecuencia objeto de medidas de salvaguarda desde 1995 son los siguientes:

Sector IV.- Productos de las industrias alimentarias; bebidas, líquidos alcohólicos y vinagre; tabaco y sucedáneos del tabaco elaborados (12)

Sector VI.- Productos de las industrias químicas o de las industrias conexas (23) y

Sector XV.- Metales comunes y manufacturas de esos metales (13).

Los datos reportados no incluyen las notificaciones de las medidas adoptadas en aplicación del artículo 5o. del Acuerdo sobre la Agricultura o de la sección 16 del Protocolo de Adhesión de la República Popular China.

Cabe destacar que para 2002, ninguno de los casos planteados en materia de medidas de salvaguarda ante los grupos especiales y el órgano de apelación fueron considerados consistentes con las disposiciones sobre salvaguardas del organismo multilateral. ${ }^{61}$ Lo anterior muestra una

${ }^{61}$ Lee, Yong-Shik, “Safeguard Measures...”, op. cit., p. 642. 
aparente falta de aptitud por parte de los países miembros para cumplir con el ASG. ${ }^{62}$

\section{CRISIS ECONÓMICA Y MEDIDAS ANTIDUMPING ${ }^{63}$}

Las medidas de salvaguarda parecen a primera vista menos atractivas en términos de alivio comercial que las medidas antidumping y antisubsidios. En general debido a que deben compensarse y tienen límites temporales más estrictos ( 8 y 10 años, dependiendo si es un país en vías de desarrollo el que aplique la medida), además de que se imponen en contra de un comercio leal y llevan a la admisión por parte de las industrias domésticas de que no pueden competir con bienes importados en condiciones de comercio leal. Además, la imposición de medidas de salvaguarda puede aumentar la tensión en las relaciones comerciales internacionales dado su carácter sancionador del comercio leal. ${ }^{64}$

Sin embargo, la experiencia nos muestra que las medidas de salvaguarda son instrumentos contundentes que pueden llevar a medidas de protección para una amplia gama de productos. ${ }^{65}$

Conforme a la información reportada por la $\mathrm{OMC},{ }^{66}$ entre julio y diciembre de 2008, 15 miembros de la OMC comunicaron que habían iniciado un total de 120 nuevas investigaciones antidumping, frente a 103 nuevas investigaciones notificadas por 14 miembros en el mismo periodo de 2007.

62 Ibidem, p. 463

63 Incluimos referencias a las medidas antidumping al ser este mecanismo una de las opciones de defensa comercial mayormente utilizadas.

${ }^{64}$ Giovan, Ileana Di, “Salvaguardias en el Mercosur”, La Ley, Buenos Aires, año LXIII, núm. 157, 19 de agosto de 1999 , p. 3.

65 Vermulst, Edwin, Marta Pernaute y Lucenti, Krista, "Recent European Community Safeguards Policy: 'Kill them all and let God sort them out'?”, Journal of World Trade, Ginebra, Kluwer Law International, vol. 38, núm. 6, diciembre de 2004, p. 955.

66 Press/556, 7 de mayo de 2009, "La Secretaría de la OMC comunica un incremento de las nuevas investigaciones antidumping" http://www.wto.org/spanish/news_s/pres09_s/ pr556_s.htm. Información contenida en los documentos de la serie G/ADP/N/180. Consultado el 5 de septiembre de 2011. 
En 2008 se iniciaron 208 investigaciones antidumping, frente a 163 en 2007 y 202 en 2006.

El miembro que notificó el mayor número de investigaciones iniciadas durante el periodo de julio a diciembre de 2008 fue la India (42), seguida por Brasil (16), China (11), Turquía (10), la Argentina y las Comunidades Europeas (9 cada uno), Indonesia (6), Ucrania (4), los Estados Unidos y Pakistán (3), Australia y Colombia (2 cada uno) y Canadá, Corea y México (1 cada uno).

El país objeto del mayor número de nuevas investigaciones fue China, con 34 investigaciones iniciadas contra sus exportaciones, lo que supone un descenso del $17 \%$ con respecto a las 40 nuevas investigaciones que se habían iniciado entre julio y diciembre de 2007 contra las exportaciones de este país. A continuación se encuentran las Comunidades Europeas (incluidos distintos Estados miembros individualmente), con 14 nuevas investigaciones iniciadas contra sus exportaciones, seguidas de los Estados Unidos, el Taipei Chino y Tailandia (6 cada uno), Corea, Indonesia y Malasia ( 5 cada uno), Arabia Saudita y la India (4 cada uno), e Irán y Turquía (3 cada uno). Tras ellos figuran Australia, Bielorrusia, Hong Kong, China, Japón, Rusia, Sudáfrica y Ucrania (2 cada uno), y Argentina, Armenia, Brasil, Chile, Ecuador, Filipinas, Israel, Kazajstán, Kuwait, Perú y Sri Lanka (1 cada uno).

En total, 11 miembros comunicaron que habían aplicado 81 nuevas medidas antidumping definitivas en el segundo semestre de 2008, lo que representa un aumento del $45 \%$ con respecto a las 56 nuevas medidas notificadas por 14 miembros en el mismo periodo de 2007. Hay que destacar, sin embargo, que estas nuevas medidas definitivas son el resultado de investigaciones iniciadas principalmente en 2007 (desde la iniciación de una investigación hasta la imposición de una medida antidumping definitiva puede transcurrir año y medio).

Durante el segundo semestre de 2008, los miembros desarrollados iniciaron 15 nuevas investigaciones y aplicaron 36 de las 81 nuevas medidas definitivas, mientras que en el primer semestre de 2007 esos miembros habían iniciado 35 nuevas investigaciones y aplicado 11 nuevas medidas.

En cuanto a la aplicación de nuevas medidas antidumping definitivas, los Estados Unidos notificaron que durante el periodo de julio a 
diciembre de 2008 habían aplicado 21 nuevas medidas, lo que representa un aumento importante con respecto a las dos nuevas medidas que habían notificado en el segundo semestre de 2007. Estas medidas son resultado de investigaciones iniciadas principalmente en 2007, es decir, mucho antes del último periodo de notificación. La India, con 13 nuevas medidas notificadas durante el primer semestre de 2008, ocupó el segundo lugar, seguida de Turquía (11 nuevas medidas), Brasil (8), las Comunidades Europeas (6), Argentina (3) y Egipto (1 medida). Corea, que no había notificado ninguna nueva medida en el segundo semestre de 2007, notificó 10 nuevas medidas en el mismo periodo de 2008. Japón, Australia y Canadá notificaron 4, 3 y 2 nuevas medidas respectivamente, en el primer semestre de 2008, pero no notificaron ninguna medida en el mismo periodo de 2007. China, Colombia, Israel y Tailandia, que habían notificado nuevas medidas en el segundo semestre de 2007, no notificaron ninguna nueva medida en el mismo periodo de 2008.

Cabe destacar que en 2009 se iniciaron 97 nuevas investigaciones notificadas por 18 miembros del organismo internacional. Se aplicaron 62 nuevas medidas antidumping por 16 miembros en el mismo periodo.

En diciembre de 2010 la Secretaría de la OMC informó que en el periodo comprendido entre el 1o. de enero y el 30 de junio de 2010 hubo una disminución del 29\% en el número de iniciaciones de investigaciones antidumping en relación con el periodo correspondiente de 2009. También informó que disminuyó el número de nuevas medidas aplicadas durante el primer semestre de 2010 en relación con el primer semestre de 2009. ${ }^{67}$

Entre enero y junio de 2010, 19 miembros de la OMC iniciaron 69 nuevas investigaciones, frente a las 97 nuevas investigaciones notificadas por 18 miembros durante el mismo periodo de 2009. Catorce miembros comunicaron que habían aplicado 59 nuevas medidas antidumping en el primer semestre de 2010, lo que representa una disminución del $5 \%$ con respecto a las 62 nuevas medidas notificadas por 16 miembros en el mismo periodo de 2009. Durante el primer semestre de 2010, los miembros desarrollados iniciaron 15 nuevas investigaciones y aplicaron

67 Press /623, 6 de diciembre de 2010, "La Secretaría de la OMC informa sobre la disminución del número de investigaciones y medidas antidumping", http: / /www.wto.org/spanish/ news_s/pres10_s/pr623_s.htm. Consultado el 5 de septiembre de 2011. 
10 de las 59 nuevas medidas definitivas, mientras que en el primer semestre de 2009 esos miembros habían iniciado 15 nuevas investigaciones y aplicado 15 nuevas medidas.

Específicamente, los miembros que notificaron el mayor número de nuevas investigaciones entre enero y junio de 2010 fueron la India, Unión Europea, Argentina, Brasil e Israel. Otros miembros que notificaron la iniciación de investigaciones fueron Australia, China, Corea, Indonesia, Colombia, Estados Unidos, Tailandia, Canadá, Chile, Jamaica, México, Taipei Chino, Turquía y Ucrania. Cabe destacar que según el informe de la OMC, en el caso de México, el número de investigaciones iniciadas no varió en relación con las cifras notificadas en el periodo comprendido entre enero y junio de 2009.

El país objeto del mayor número de nuevas investigaciones en el primer semestre de 2010 fue China, con 23 investigaciones iniciadas contra sus exportaciones, seguida por la Unión Europea con 11 nuevas investigaciones iniciadas, Estados Unidos con 5, Corea y Tailandia con 4 cada uno, Malasia y Taipei Chino con 3 cada uno, Brasil y Japón con 2 cada uno y Bielorrusia, Bosnia y Herzegovina, Chile, la India, Indonesia, México, Noruega, la República Dominicana, Singapur, Sudáfrica, Ucrania y Vietnam con 1 cada uno.

\section{LAS MEDIDAS DE SALVAGUARDA EN LOS MECANISMOS}

DE INTEGRACIÓN REGIONAL IBEROAMERICANO: MERCOSUR Y ALADI

En mecanismos de integración como es el caso del Mercosur se ha planteado el tema de si las medidas de salvaguarda están permitidas o no y de si puede negarse a una parte interesada la aplicación de una medida de salvaguarda prevista en otros acuerdos multilaterales como es el Acuerdo de Textiles y del Vestido de la OMC, pese a que existe un vacío legal en el Mercosur frente a normas especiales como el ATV en el marco de la OMC.

En el caso planteado entre Brasil y Argentina la decisión arbitral adoptada conforme al Protocolo de Brasilia, partió del hecho de que el Tratado de asunción explícitamente excluyó el uso de salvaguardas 
dentro del Mercosur conforme al artículo 5o. del Anexo IV a partir del 31 de diciembre de 1994, negando la procedencia de la salvaguarda impuesta por Argentina. ${ }^{68}$

En el marco de la ALADI, existe el Mecanismo de Notificación de Medidas de Salvaguardia adoptado el 24 de setiembre de 2008 por el Comité de Representantes mediante la Resolución $336 .{ }^{69}$

Su objetivo es que las medidas de salvaguardas que se aplican en el marco de los acuerdos negociados en la ALADI sean de conocimiento de todos los países de la región con el propósito de advertirles en forma oportuna sobre los giros que pueden ir tomando las ventajas arancelarias pactadas en los mismos. Para ello, cuando un país miembro inicie un proceso de investigación o aplique una medida de salvaguarda en el ámbito de los acuerdos suscritos en el marco del Tratado de Montevideo de 1980, deberá comunicarlo en un plazo de 15 días a la Secretaría General de la ALADI (SG).

Conforme a la información disponible en el mecanismo señalado, actualmente Ecuador ha impuesto una salvaguarda por balanza de pagos ${ }^{70}$ mediante Resolución 466 publicada en el Registro Oficial 512 del 22 de enero de 2009 por el Pleno del Consejo de Comercio Exterior e Inversiones, conforme al artículo XVIII, Sección B, del GATT. ${ }^{71}$

Dicha salvaguarda también fue aprobada por la Secretaría General de la Comunidad Andina ${ }^{72}$ y podrá mantenerse hasta 2010 mediante la resolución 1227 de la misma, pudiendo "extender al comercio intrasubregional" de productos originarios de la Comunidad Andina "la

68 Peña, Félix, "El laudo arbitral sobre las salvaguardias textiles en el Mercosur”, La Ley, Buenos Aires, año LXIV, núm. 90, 10 de mayo de 2000, p. 1.

${ }^{69}$ Mecanismo sobre notificación de medidas de salvaguardia preferenciales ALADI/CR/ Resolución 336.

70 Resolución núm. 466 (.pdf) de 19/01/09 publicada en el Diario Oficial del 22 de febrero de 2009, COMEXI.

Resolución núm. 467 (.pdf) de 22 de enero de 2009, COMEXI.

Anexo a la Resolución núm. 467(.pdf) de 22 de enero de 2009, COMEXI.

Resolución núm. 468 (.pdf) de 30 de enero de 2009, COMEXI.

Resolución núm. 470 (.pdf) de fecha 19 de febrero de 2009, COMEXI.

Resolución núm. 471 (.pdf) de fecha 19 de febrero de 2009, COMEXI.

71 Véase Resolución núm. 471 (.pdf) de fecha 19 de febrero de 2009. COMEXI

72 Comunidad Andina autoriza a Ecuador a aplicar salvaguardas hasta 2010 RPP NOTICIAS.mht. 
aplicación de recargos ad valorem y específicos, así como cuotas a la importación de mercancías" debido a "la difícil situación económica que atraviesa Ecuador" y que "existieron motivos razonables para temer efectos potencialmente riesgosos” para la economía de ese país.

\section{CONCLUSIÓN}

Señala Lee que si no se tiene un fuerte sentido de multilateralismo el sistema de comercio mundial será vulnerable al proteccionismo, lo que solamente nos llevará a disputas y retaliaciones que reducirán el comercio y sus beneficios.

Las salvaguardas deberán aplicarse en congruencia con el AGS previo examen de la necesidad real de restricciones de emergencia a las importaciones. La aplicación de medidas de salvaguarda basadas solamente en consideraciones políticas sin la debida justificación económica y jurídica solamente llevará a otros miembros a hacer lo propio. ${ }^{73}$

Una medida de salvaguarda como excepción al libre comercio puede tender a lastimar los principios básicos del GATT-OMC si se imponen abusando del proteccionismo. ${ }^{74}$ Las crisis económicas históricamente han resultado en un incremento del proteccionismo, de ahí que la observancia de la disciplina en materia de salvaguardas es de gran importancia en estos momentos.

Dichas medidas pueden constituirse en un eficaz mecanismo de defensa para las industrias nacionales frente a las desviaciones de comercio ocasionadas por la crisis económica en la que se encuentra sumida la economía mundial. Los países en desarrollo, caso de México (en particular en productos como calzado, textiles, vestidos, bicicletas y juguetes), tienen en las medidas de salvaguarda una opción de defensa comercial que aunada con los procedimientos antidumping en su caso protejan el desarrollo agroindustrial e industrial interno.

73 Lee, Yong-Shik, "Safeguard Measures...”, op. cit., p. 671-673.

74 Mueller, Felix, op. cit., p. 1120. 
Deben pues mirarse como una opción de transición hacia la estabilidad económica internacional.

\section{BIBLIOGRAFÍA, HEMEROGRAFÍA Y FUENTES ${ }^{75}$}

\section{Bibliografía}

BAhla, Raj y Kennedy, Kevin, World Trade Law, USA, Lexis Law Publishing, 1998.

Cruz Miramontes, Rodolfo, "Aspectos generales del intercambio comercial internacional. Su regulación y efectos, en particular a las relaciones entre México y los Estados Unidos de Norteamérica”, en Barra Mexicana, Colegio de Abogados, La nueva Ley de Comercio Exterior, México, Porrúa, 1987.

JACKSON, John H., The jurisprudence of GATT \& the WTO, Cambridge, Cambridge University Press, 2000. 2002.

- World Trade and the Law of GATT, USA, 1969.

- et al., Legal problems of international economic relations, St. Paul, Minnesota, West Publishing, 1995.

FERnÁndez Rozas, José Carlos, Sistema del comercio internacional, Madrid, Civitas, 2001.

SaldaÑa PÉreZ, Juan Manuel, Comercio Internacional, México, Porrúa, 2008.

\section{Hemerografía}

Giovan, Ileana Di, "Salvaguardias en el Mercosur", La Ley, Buenos Aires, año LXIII, núm. 157, 19 de agosto de 1999.

Bronckers, Marco C. E. J., "WTO implementation in the European Community. Antidumping, Safeguards and Intellectual Property",

75 Incluimos únicamente la bibliografía, hemerografía y fuentes citadas. 
Journal of World Trade, Ginebra, Kluwer Kaw International, vol. 29, núm. 5, octubre de 1995.

LEE, Yong-Shik, "Critical issues in the Application of the WTO Rules on Safeguards. In the light of the recent panel reports and the Appellate Body decisions", en Journal of World Trade, Ginebra, Kluwer Kaw International, vol. 34, núm. 2, abril de 2000.

, "Destabilization of the Discipline on Safeguards? Inherent problems with continuing application of Article XIX after the settlement of the Agreement on Safeguards", Journal of World Trade, Ginebra, Kluwer Kaw International, vol. 35, núm. 6, diciembre de 2001. , "Review of the first WTO Panel Case on the Agreement on Safeguards. Korea-Definitive measure on imports of certain daily products and its implications for the application of the Agreement", Journal of World Trade, Ginebra, Kluwer Kaw International, vol. 33, núm. 6, diciembre de 1999.

, "Safeguard Measures: why are they not applied consistently with the rules. Lessons for competent national authorities and proposal for the modification of the rules on safeguards", Journal of World Trade, Ginebra, Kluwer Kaw International, vol. 36, núm. 4, agosto de 2002.

,"Test of multilateralism in international trade: U.S. Steel Safeguards", Northwestern Journal of International Law \& Business, Estados Unidos, vol. 25, núm. 1, Otoño de 2004.

,"Revival of Grey-Area Measures? The US-Canada Softwood Lumber Agreement: Conflict with the WTO Agreement on Safeguards", en Journal of World Trade, Ginebra, Kluwer Kaw International, vol. 36, núm. 1, febrero de 2002.

Mueller, Felix, "Is the General Agreement on Tariffs and Trade Article XIX "Unforseen Developments Clause" still effective under the Agreement on Safeguards?, Journal of World Trade, Ginebra, Kluwer Kaw International, vol. 37, núm. 6, diciembre de 2003.

PEÑA, Félix, "El laudo arbitral sobre las salvaguardias textiles en el Mercosur", La Ley, Buenos Aires, año LXIV, núm. 90, 10 de mayo de 2000.

SPADI, Fabio "Discriminatory Safeguards in the light of the Adminission of the People's Republic of China to the World Trade Organization", Journal of International Economic Law, vol. 5, núm. 2, junio de 2002. 
TREBILCOCK, Michael J. y HOWSE, Robert, The regulation of international trade, Londres, Routledge, 1995.

Vermulst, Edwin et al., "Recent European Community Safeguards Policy: "Kill them all and let God sort them out"?, Journal of World Trade, Ginebra, Kluwer Kaw International, vol. 38, núm. 6, diciembre, de 2004.

Fuentes

"Withdrawal by the United States of a Tariff Concession under Article XIX of the General Agreement", GATT/CP/106 22 - october, 1951. Birch Playwood Doors Kins USITIC, Pub 743, October 1975. Stainless Steel Table Flatware USITIC Pub 739, 1976 (periodo de 8 años) - Sugar USITIC Pub 207, 1977 - Stainless Steel and Alloy tool Steel - USITICPub 156, 1976 (once años).

DECRETO por el que se modifica la Tarifa de la Ley de los Impuestos Generales de Importación y de Exportación publicado en el Diario Oficial de la Federación de México del 24 de diciembre del 2008.

Exec. Order no. 9832,3 C.F.R. Secc. 624, 625 (II, 25-1947).

Executive Branch GATT Studies Committee on finance United States Senate, March 1974.

Ley de Comercio Exterior, consultable en su versión electrónica en http: / / www.ordenjuridico.gob. $\mathrm{mx}_{\mathrm{N}}$ Federal/Combo/L-21.pdf.

Mecanismo sobre notificación de medidas de salvaguardia preferenciales ALADI/CR/Resolución 336.

OCDE International Trade Statistics: Trade flows collapse in Q4 2008 but signs of falls easing in early 2009, 30 de abril de 2009, en http: / / www. oecd.org/dataoecd/29/36/42668007.pdf.

OCDE titulado La Crisis Financiera Global y Créditos a la Exportación fechado en París el 22 de abril de 2009.

Reglamento de la Ley de Comercio Exterior.

Resolución núm. 466 (.pdf) del 19 de enero de 2009 publicada en el Diario Oficial del 22 de febrero de 2009, COMEXI.

Resolución núm. 467 (.pdf) del 22 de enero de 2009, COMEXI.

Anexo a la Resolución $\mathrm{N}^{\circ}$ 467(.pdf) del 22 de enero de 2009, COMEXI.

Resolución núm. 468 (.pdf) del 30 de enero de 2009, COMEXI.

Resolución núm. 470 (.pdf) de fecha 19 de febrero de 2009, COMEXI. 
Resolución núm. 471 (.pdf) de fecha 19 de febrero de 2009, COMEXI. Secc. 201 Relief, 19 CFR, Part 206, 29 August 1988 Regulatory Requirements.

Text of Geneva Draft Charter for an International Trade Organization - International Conciliation, Nueva York, octubre de 1947.

Trade Act. of 1974 (19 U. S. C. 2251-2253 de los Estados Unidos).

Tratado de Comercio entre México y los Estados Unidos de América celebrado el 23 de diciembre de 1942.

Womes fur felt hats and bodies" - GATT/CP/106, 1950 - 1956.

$\mathrm{WT} / \mathrm{DS} 8 / \mathrm{AB} / \mathrm{R}, \mathrm{WT} / \mathrm{DS} / 10 / \mathrm{AB} / \mathrm{R}$ y WT/DS/11/AB/R de 1 o. de noviembre de 1996.

WT/DS87/AB/R, WT/DS/110/AB/R de 13 de diciembre de 1999. Informe del Órgano de Apelación.

WT/DS121/AB/R del 14 de diciembre de 1999.

WT/DS121/AB/R del 14 de diciembre de 1999, Informe del Órgano de Apelación.

WT/DS121/R, del 25 de junio de 1999, Informe del Grupo Especial.

WT/DS166/AB/R del 22 de diciembre de 2000. Informe del Órgano de Apelación.

WT/DS177/AB/R, WT/DS178/AB/R del 1o. de mayo de 2001, Informe del Órgano de Apelación.

WT/DS177/R, WT/DS178/R del 21 de diciembre de 2000, Informe del Grupo Especial.

WT/DS98/AB/R del 14 de diciembre de 1999. Informe del Órgano de Apelación.

WT/DS98/R, del 21 de junio de 1999, Informe del Grupo Especial.

WTO, Guide to GATT Law and Practice, Geneva, 1995.

XIV Observatorio Económico FAES, Madrid, 15 de octubre de 2008. documentos.fundacionfaes.info/document_file/filename/2231/14_OB SERVATORIO_OK_FINALO3.pdf.

"La Secretaría de la OMC comunica un incremento de las nuevas investigaciones antidumping", http://www.wto.org/spanish/news_s/ pres09_s/pr556_s.htm.

"La Secretaría de la OMC informa sobre la disminución del número de investigaciones y medidas antidumping", http://www.wto.org/spa nish/news_s/pres10_s/pr623_s.htm. 